\title{
Outcomes of General Anesthesia and Conscious Sedation in Endovascular Treatment for Stroke
}

\author{
Caroline Just, Philippe Rizek, Peter Tryphonopoulos, David Pelz, Miguel Arango
}

\begin{abstract}
Background: Recent studies have strongly indicated the benefits of endovascular therapy for acute ischemic stroke, but what remains a continued debate is the role for general anaesthesia versus conscious sedation (CS) for such procedures. Retrospective studies have found poorer neurological outcomes in patients who underwent general anesthesia (GA); however, some have revealed worse baseline stroke severity in these patients. Methods: This study is a retrospective cohort study aimed at comparing mortality and morbidity of GA versus CS in patients treated with endovascular intervention in acute ischemic stroke. Chi-square and t-test analyses were used. Results: Patients in the GA $(\mathrm{n}=42)$ group were more likely to be deceased than those in the CS $(\mathrm{n}=67)$ group at hospital discharge, 3 months, and 6 months poststroke onset. Morbidity, as defined by modified Rankin Score, was significantly greater in the GA group at hospital discharge, and a similar trend was seen in morbidity at 3 months postdischarge. Conclusion: General anesthesia for endovascular intervention in acute ischemic stroke was associated with increased mortality and poorer neurological incomes compared with conscious sedation. In our study, age, gender, history of hypertension, history of diabetes, and baseline National Institute of Health Stroke Scale were not significantly different between the groups. Although the need for a randomized, prospective study on this topic is clear, our study represents further corroboration of the safety and efficacy of conscious sedation in these procedures.
\end{abstract}

RÉSUMÉ: Résultats de l'anesthésie générale et de la sédation consciente dans le traitement endovasculaire de l'accident vasculaire cérébral. Contexte : Des études récentes ont montré clairement les bénéfices du traitement endovasculaire de l'accident vasculaire cérébral aigu ischémique (AVCI). Cependant le débat sur l'utilisation de l'anesthésie générale versus la sédation consciente (SC) lors de telles interventions se poursuit. Des études rétrospectives ont révélé que les résultats neurologiques étaient moins bons chez les patients qui avaient subi une anesthésie générale (AG). Cependant, selon certaines études, l'AVC était plus sévère chez ces patients. Méthodologie : Nous avons effectué une étude de cohorte rétrospective dans le but de comparer la mortalité et la morbidité de l'AG et celle de la SC chez des patients qui avaient subi une intervention endovasculaire pour un AVCI. Nous avons utilisé le test du chi-carré et le test de t pour analyser les données. Résultats : Les patients du groupe AG $(\mathrm{n}=42)$ étaient plus susceptibles d'être décédés que ceux du groupe SC $(n=67)$ soit au moment du congé hospitalier, 3 mois et 6 mois après le début de l'AVC. La morbidité, évaluée au moyen du score modifié de Rankin, était significativement plus importante dans le groupe AG au moment du congé hospitalier et on notait une tendance similaire 3 mois après le congé hospitalier. Conclusion : L'anesthésie générale lors d'une intervention endovasculaire pour un AVCI était associée à une plus grande mortalité et à des résultats neurologiques moins bons par rapport à la sédation consciente. Dans notre étude, l'âge, le sexe, l'histoire d'hypertension, l'histoire de diabète et le score initial au National Institute of Health Stroke Scale n'étaient pas significativement différents entre les deux groupes. Bien qu'une étude prospective randomisée sur ce sujet soit nécessaire, notre étude corrobore la sécurité et l'efficacité de la SC lors de ces interventions.

Keywords: anaesthesia, cerebrovascular disease, cerebrovascular surgery, endovascular, interventional neuroradiology, neurosurgery vascular, neurovascular, stroke

doi:10.1017/cjn.2016.256

Can J Neurol Sci. 2016; 43: 655-658

The role of rapid endovascular treatment in acute ischemic stroke has become increasingly supported by recent literature. ${ }^{1,2}$ The Multicenter Randomized Clinical Trial of Endovascular Treatment for Acute Ischemic Stroke in the Netherlands as well as The Endovascular Treatment for Small Core and Anterior Circulation Proximal Occlusion with Emphasis on Minimizing CT to Recanalization Times both yielded results in favor of rapid endovascular treatment. What is less clear, however, is the method of anesthesia that is more likely to be associated with positive outcomes.

Previous research has shown the need for further investigation into the consequences of general anesthesia (GA) versus conscious sedation (CS). ${ }^{3,4}$ Heated debate has occurred around the superiority of each type of anesthesia. ${ }^{5,6}$ The key factors affecting the choice of GA versus CS include patient pain, patient

From the Clinical Neurological Sciences, Schulich School of Medicine Dentistry (CJ), Clinical Neurological Sciences (PR), Department of Anesthesiology (PT, MA),

Department of Medical Imaging (DP), Western University, London, Ontario, Canada. Received May 30, 2015. Final Revisions Submitted January 17, 2016. Date of ACCEPTANCE March 17, 2016.

Correspondence to: Caroline Just, Department of Clinical Neurological Sciences,

Schulich School of Medicine and Dentistry, Western University, 339 Windermere Rd,

London ON, N6A 5A5, Canada. Email: Caroline.just@medportal.ca 
movement, time delays, and hemodynamic parameters, particularly blood pressure. GA provides greater control of patient pain and movement compared with CS, but presents greater hemodynamic instability, risk for aspiration, ${ }^{7}$ and postulated time delays. Several literature reviews provide more detail of these issues. ${ }^{8-10}$

The current study used a retrospective design to compare morbidity and mortality of type of anesthesia in patients who received endovascular treatment in the setting of acute ischemic stroke using CS versus GA.

\section{METHODS}

The study is a retrospective cohort study of neurologic outcome and mortality in patients receiving endovascular therapy for acute ischemic stroke from November 2000 to March 2013 at University Hospital, London Health Sciences Centre, London, Ontario, Canada. London Health Sciences Centre is the regional stroke center for the Southwestern Ontario Stroke strategy. It services a population of approximately 1.6 million, as of $2013 .^{11}$

Patient characteristics that were collected were chosen based on projected influence on outcome, and included age, gender, history of diabetes, history of hypertension, and smoking history. Data were also collected on initial National Institute of Health Stroke Scale (NIHSS), initial Glasgow Coma Scale, time from initial imaging (usually computed tomography) to initiation of neurointerventional procedure, hypoxia or hypotension at induction, hypoxia or hypotension transoperatively, and agitation (at any point during the procedure, including at induction).

Patients included in the initial chart review were all who underwent a neuro-interventional stroke procedure at University Hospital between November 2000 and March 2013. This yielded 137 patients. Patients were excluded if their procedure was an aneurysm repair (15 cases), carotid stenting (four cases), an extracranial-intracranial bypass (one case). One patient was excluded because no intervention was actually performed as a result of rapid patient decline before endovascular treatment was initiated. Two patients were excluded because data on which type of anesthesia was used were not available; another was excluded because conversion from CS to GA occurred because of patient agitation. The decision to exclude this patient, rather than include the patient in the GA analysis, was made to simplify our analysis and avoid having data from a patient who actually received both CS and GA. All procedures were performed by one of seven experienced neuro-interventionalists. Techniques used included intra-arterial injection of thrombolytics, mechanical thrombectomy, and thromboaspiration.

An anesthesiologist was present during all procedures. For the purposes of our study, GA was defined as the use of artificial means of ventilation. The decision to use GA or CS was made by the anesthesiologist during all procedures. The major factor influencing the decision to use GA was patient agitation and movement. Table 1 compares baseline characteristics of each group, indicating that patients who underwent GA were not significantly sicker than those who underwent CS.

Neurologic outcome was measured with the modified Rankin Score (mRS), recorded at discharge, 3 months after stroke onset, and 6 months after stroke onset. ${ }^{11} \mathrm{mRS}$ scores were stratified into "good outcome" (mRS 0-2) and "poor outcome" (mRS 3-6). Mortality was also recorded at discharge, 3 months after stroke onset, and 6 months after stroke onset.

Data were entered first into a Microsoft Excel Spreadsheet, and then imported into SPSS, which was used for analysis. Chi-square and independent-sample t-tests were both used, depending on the nature of the variable. $p$ values less than 0.05 were used to indicate statistical significance, and all tests of hypotheses were two-sided. In cases where patients were lost to follow-up, the most recent mRS score was carried over. Several descriptive analyses were also run to compare patient characteristics in each group.

\section{ReSUlts}

Of the 109 patients included in the analysis, $42(38.5 \%)$ underwent GA for their procedure and 67 (61.5\%) had CS.

Table 1 displays the various patient demographic and clinical characteristics that were collected for the GA group and the CS group. Chi-square and t-test analyses were used to illustrate that, with the exception of smoking status, the demographic characteristics, including age, gender, history of hypertension, history of type 1 or type 2 diabetes, baseline NIHSS, time from imaging to anesthesia, duration of procedure, and time from imaging to end

Table 1: Baseline characteristics of both groups.

\begin{tabular}{|c|c|c|c|}
\hline Variable & General anesthesia $(n=42)$ & Conscious sedation $(n=67)$ & Chi-square or t-test $p$ value \\
\hline Age (mean) & 60.4 & 62.9 & 0.361 \\
\hline Gender & 17 females $(40 \%)$ & 25 females $(37 \%)$ & 0.741 \\
\hline History of smoking & $25(60 \%)$ & $27(40 \%)$ & $0.050 *$ \\
\hline History of hypertension & $24(57 \%)$ & $37(55 \%)$ & 0.844 \\
\hline History of DM1 & $2(5 \%)$ & $3(5 \%)$ & 0.945 \\
\hline History of DM2 & $7(17 \%)$ & $7(10 \%)$ & 0.345 \\
\hline NIHSS (mean) & 13.36 & 12.88 & 0.771 \\
\hline Time from imaging to procedure & 270 & 229 & 0.292 \\
\hline Duration of procedure & 239 & 212 & 0.176 \\
\hline Time from imaging to end of procedure & 514 & 432 & 0.122 \\
\hline
\end{tabular}

*Indicates significance where the $\mathrm{p}$ value is $<0.05$.

DM1 = insulin-dependent diabetes; DM2 = non-insulin-dependent diabetes; NIHSS = National Institute of Health Stroke Scale. 
Table 2: Results: Morbidity and mortality in both groups.

\begin{tabular}{|c|c|c|c|c|}
\hline & General anesthesia & Conscious sedation & Chi-square results & t-test and $p$ value results \\
\hline \multirow[t]{2}{*}{ Mortality in hospital } & $17(40.5 \%)$ & $12(17.9 \%)$ & $X^{2}=6.73$ & - \\
\hline & & & $\mathrm{p}=0.009 *$ & \\
\hline \multirow[t]{2}{*}{ Mortality at 3 months } & $18(42.9 \%)$ & $14(20.9 \%)$ & $X^{2}=6.00$ & - \\
\hline & & & $\mathrm{p}=0.014 *$ & \\
\hline \multirow[t]{2}{*}{ Mortality at 6 months } & $18(42.9 \%)$ & $16(23.9 \%)$ & $\mathrm{X}^{2}=4.33$ & - \\
\hline & & & $\mathrm{p}=0.014 *$ & \\
\hline \multirow[t]{2}{*}{ Morbidity at Discharge $(\mathrm{mRS}>2)$} & $32(76.2 \%)$ & $42(62.7 \%)$ & $\mathrm{X}^{2}=2.16$ & $\mathrm{t}=2.17$ \\
\hline & & & $\mathrm{p}=0.142$ & $\mathrm{p}=0.032 *$ \\
\hline \multirow[t]{2}{*}{ Morbidity at 3 months (mRS > 2) } & $28(66.7 \%)$ & $36(53.7 \%)$ & $X^{2}=1.78$ & $t=1.96$ \\
\hline & & & $\mathrm{p}=0.182$ & $\mathrm{p}=0.052$ \\
\hline \multirow[t]{2}{*}{ Morbidity at 6 months $(m R S>2)$} & $26(61.9 \%)$ & $35(52.2 \%)$ & $\mathrm{X}^{2}=.979$ & $\mathrm{t}=1.96$ \\
\hline & & & $\mathrm{p}=0.123$ & $\mathrm{p}=0.069$ \\
\hline
\end{tabular}

*Indicates significance where the $\mathrm{p}$ value is $<0.05$.

$\mathrm{mRS}=$ modified Rankin Score

of procedure (i.e. the sum of the previous two variables) were not significantly different between the groups.

\section{Mortality in Hospital}

Of the 42 patients in the GA group, 17 (40.5\%) died in the hospital (Table 2). Of the 67 patients in the CS group, 12 (17.9\%) died in the hospital. This distribution was significantly different (Pearson's chi-square $=6.73, \mathrm{p}=0.009$ ).

\section{Mortality at 3 Months After Stroke Onset}

Of the 42 patients in the GA group, 18 (42.9\%) had died at 3 months poststroke onset. Of the 67 patients in the CS group, $14(20.9 \%)$ had died at 3 months poststroke onset. This distribution was significantly different (Pearson's chi-square $=6.00$, $\mathrm{p}=0.014)$.

\section{Mortality at 6 Months After Stroke Onset}

Of the 42 patients in the GA group, 18 (42.9\%) had died at 6 months poststroke onset. Of the 67 patients in the CS group, $16(23.9 \%)$ had died at 6 months poststroke onset. This distribution was significantly different (Pearson's chi-square $=4.33$, $p=.037)$.

\section{Morbidity at Hospital Discharge}

Of the 42 patients in the GA group, 32 (76.2\%) were dependent on others for activities of daily living (ADLs), bedbound, or deceased (i.e. $m R S>2$ ). Of the 67 patients in the $\mathrm{CS}$ group, $42(62.7 \%)$ were dependent on others for ADLs, bedbound, or deceased (i.e. $\mathrm{mRS}>2$ ). ${ }^{12}$ This distribution was not significantly different from that expected by chance (Pearson's chi-square = 2.16, $\mathrm{p}=0.142$ ). However, when actual $\mathrm{mRS}$ scores were compared using a t-test (as opposed to comparing how many patients were functionally dependent), a significant difference was found $(\mathrm{GA}$ mean $=4.00, \mathrm{CS}$ mean $=3.15, \mathrm{t}=2.17, \mathrm{p}=0.032)$.

\section{Morbidity at 3 Months After Stroke Onset}

Of the 42 patients in the GA group, $28(66.7 \%)$ were dependent on others for ADLs, bedbound, or deceased (i.e. $\mathrm{mRS}>2$ ). Of the 67 patients in the CS group, 36 (53.7 \%) were dependent on others for ADLs, bedbound, or deceased (i.e. $\mathrm{mRS}>2$ ). This distribution was not significantly different from that expected by chance (Pearson's chi-square 1.78; $\mathrm{p}=0.182$ ). As stated previously, a t-test was also done, which approached statistical significance but was only a trend $(\mathrm{GA}$ mean $=3.74, \mathrm{CS}$ mean $=2.91, \mathrm{t}=1.96, \mathrm{p}=0.052)$.

\section{Morbidity at 6 Months Poststroke Onset}

Of the 42 patients in the GA group, $26(61.9 \%)$ were dependent on others for ADLs, bedbound, or deceased (i.e. $\mathrm{mRS}>2$ ). Of the 67 patients in the CS group, $35(52.2 \%)$ were dependent on others for ADLs, bedbound, or deceased (i.e. $\mathrm{mRS}>2$ ). This distribution was not significantly different from that expected by chance (Pearson's chi-square, $0.979 ; \mathrm{p}=0.323$ ). As mentioned previously, a t-test was also done, which was not significant $(\mathrm{GA}$ mean $=3.67, \mathrm{CS}$ mean $=2.87, \mathrm{t}=1.96, \mathrm{p}=0.069)$.

Table 3 describes location of thrombus; the vast majority (as stroke demographics would suggest) were located in the middle cerebral artery.

Table 3: Distribution of thrombus location.

\begin{tabular}{l|c|c}
\hline Thrombus location & Number of cases & Percentage of total \\
\hline ICA & 5 & 4.6 \\
\hline ACA & 4 & 3.7 \\
\hline MCA & 72 & 66.1 \\
\hline Basilar artery & 25 & 22.5 \\
\hline Venous thrombosis & 2 & 1.8 \\
\hline PCA & 1 & 0.9 \\
\hline
\end{tabular}

$\mathrm{ACA}=$ anterior cerebral artery; $\mathrm{ICA}=$ internal cerebral artery; $\mathrm{MCA}=$ middle cerebral artery; PCA = posterior cerebral artery. 


\section{DISCUSSION}

A 2010 multicenter retrospective review of 980 patients revealed poorer neurological outcome in patients treated under GA (odds ratio, 2.33; 95\% confidence interval, 1.63-3.44; $\mathrm{p}<0.0001) .{ }^{13}$ This study represents the largest of its kind. Jumaa et al, who retrospectively compared patients who were intubated with patients who were not intubated, found that intubation was associated with longer intensive care unit stays (6.5 vs 3.2 days, $\mathrm{p}=0.0008$ ). However, a notable confounding factor in this study was a higher NIHSS score at baseline of patients who underwent intubation. ${ }^{14}$ Hassan et al, also using a retrospective design, found that even after adjustment for age, sex, and NIHSS score adjustment, intubated patients had a higher rate of aspiration pneumonia development ( $23 \%$ vs $14 \%, \mathrm{p}=0.22)$, higher mortality in-hospital (36\% vs $8.4 \%, \mathrm{p}<0.0001$ ), and higher morbidity at discharge ( $45 \%$ vs $17 \%, \mathrm{p}=0.0009){ }^{7}$ Davis et al retrospectively compared patients who underwent GA with those who had local anesthetic complimented by "light sedation" with midazolam and fentanyl. ${ }^{15}$ Results indicated that after controlling for stroke severity, outcomes were poorer in the GA group $(60 \%$ vs $15 \%, \mathrm{p}<0.0001)$. The authors pinpointed hypotension, which was more frequent in the GA group, as a contributing culprit.

Our study's results are in line with other retrospective studies that have found superior neurological incomes with CS as opposed to GA. ${ }^{7,13,15}$ We found all significant results with mortality parameters but only some significant results with morbidity parameters. It is possible that with a larger number of cases (and thus, a concordant increase in the power of the study to detect a significant difference, if present) the trends seen in our data would have been statistically significant differences.

The majority of deaths (30/35) occurred in the hospital and involved the decision to withdraw life support following a discussion regarding poor neurologic recovery.

The repeated emergence of this finding (ie, superiority of CS over GA) in multiple centers with different clinicians, different training, and likely different equipment continues to suggest that use of CS is safer than GA in these procedures.

In addition to its necessarily correlational (ie, not randomized) nature, our study has some weaknesses. Although we were able to compare baseline NIHSS scores in both groups and found no significant difference, the NIHSS does not capture all aspects of stroke severity, and it may be in these features, or in imaging criteria such as ASPECTS (Alberta Stroke Program Early CT Score), that greater predictors of neurological outcome lie. Another key parameter that we were not able to reliably access in our chart reviews was hypotension; previous authors have suggested the hemodynamic instability involved in GA as causative of increased ischemic damage in acute stroke. ${ }^{15}$ Finally, the long duration of this retrospective study (2000-2013) means that technology and technique have evolved significantly over the course of our study.

\section{CONCLUSION}

GA for endovascular intervention in acute ischemic stroke was associated with increased mortality and poorer neurological outcomes compared with CS. In our study, age, gender, history of hypertension, history of diabetes, and baseline NIHSS were not significantly different between the groups, which somewhat addresses the concern that the poorer outcomes in GA are due to a poorer clinical status in patients who are chosen (i.e. by the clinician, independent of this study) to undergo the procedure under GA. Although the need for a randomized, prospective study on this topic is remains, our study represents further corroboration of the safety and efficacy of conscious sedation in these procedures.

\section{Disclosures}

The authors do not have anything to disclose.

\section{REFERENCES}

1. Goyal M, Demchuk AM, Menon BK, et al; ESCAPE Trial Investigators. Randomized assessment of rapid endovascular treatment of ischemic stroke. N Engl J Med. 2015;372:1019-30.

2. Berkhemer OA, Fransen PS, Beumer D, et al. MR. CLEAN. A randomized trial of intraarterial treatment for acute ischemic stroke. N Engl J Med. 2015;372:11-20; [Erratum, N Engl J Med 2015; 372:394.]

3. McDonagh DL, Olson DM, Kalia JS, Gupta R, Abou-Chebl A, Zaidat OO. Anesthesia and sedation practices among neurointerventionalists during acute ischemic stroke endovascular therapy. Front Neurol. 2010;1:118.

4. Avitsian R, Somal J. Anesthetic management for intra-arterial therapy in stroke. Curr Opin Anesthesiol. 2012;25:523-32.

5. Brekenfeld C, Mattle HP, Schroth G. General is better than local anesthesia during endovascular procedures. Stroke. 2010;41: 2716-7.

6. Gupta R. Local is better than general anesthesia during endovascular acute stroke interventions. Stroke. 2010;41:2718-9.

7. Hassan AE, Chaudhry SA, Zacharatos $\mathrm{H}$, et al. Increased rate of aspiration pneumonia and poor discharge outcome among acute ischemic stroke patients following intubation for endovascular treatment. Neurocrit Care. 2012;16:246-50.

8. Froehler MT, Fifi JT, Majid A, Bhatt A, Ouyang M, McDonagh DL. Anesthesia for endovascular treatment of acute ischemic stroke. Neurology. 2012;79:S167-73.

9. John N, Mitchell P, Dowling R, Yan B. Is general anaesthesia preferable to conscious sedation in the treatment of acute ischaemic stroke with intra-arterial mechanical thrombectomy? A review of the literature. Neuroradiology. 2013;55:93-100.

10. Brinjikji W, Murad MH, Rabinstein AA, Cloft HJ, Lanzino G, Kallmes DF. Conscious sedation versus general anesthesia during endovascular acute ischemic stroke treatment: a systematic review and meta-analysis. AJNR Am J Neuroradiol. 2015;36: 525-529.

11. Lhsc.on.ca, 'June Is Stroke Month'. 2015. http://www.lhsc.on.ca/ About_Us/LHSC/Publications/Homepage/June-is-Stroke-Month80-of-Strokes-are-Preventable.htm.

12. Hong KS, Saver JL. Quantifying the value of stroke disability outcomes: WHO Global Burden of Disease Project disability weights for each level of the modified Rankin Scale. Stroke. 2009;40: 3828-3833.

13. Abou-Chebl A, Lin R, Hussain MS, Jovin TG, et al. Conscious sedation versus general anesthesia during endovascular therapy for acute anterior circulation stroke: preliminary results from a retrospective, multicenter study. Stroke. 2010;41:1175-9.

14. Jumaa MA, Zhang F, Ruiz-Ares G, et al. Comparison of safety and clinical and radiographic outcomes in endovascular stroke therapy for proximal middle cerebral artery occlusion with intubation and general anesthesia versus the nonintubated state. Stroke. 2010;41:1180-4.

15. Davis MJ, Menon BK, Baghirzada LB, et al. Anesthetic management and outcome in patients during endovascular therapy for acute stroke. Anesthesiology. 2012;116:396-405. 